\title{
Effects of Hydrogen on the Mechanical Properties of Pure Magnesium
}

\author{
Yasumasa Chino $^{1, *}$, Daiki Nishihara ${ }^{2}$, Takamichi Ueda ${ }^{2}$ and Mamoru Mabuchi ${ }^{2}$ \\ ${ }^{1}$ Materials Research Institute for Sustainable Development, National Institute of Advanced Industrial Science and Technology, \\ Nagoya 463-8560, Japan \\ ${ }^{2}$ Department of Energy Science and Technology, Graduate School of Energy Science, Kyoto University, Kyoto 606-8501, Japan
}

Tensile tests and Charpy impact tests have been performed on pure cast Mg with hydrogen concentrations of 16-35 mass ppm, where hydrogen was mainly segregated at triple junction of grain boundaries. Tensile properties were not affected by the hydrogen concentration, but crack formation at grain boundaries was enhanced by an increase in hydrogen concentration. The Charpy impact tests showed that the Mg with a higher hydrogen concentration exhibited a higher ductile-brittle transition temperature and that the temperature dependence of the Charpy impact energy was in good agreement with that of fractography. Thus, the segregation of hydrogen at grain boundaries likely induced the intergranular fracture of Mg. [doi:10.2320/matertrans.MC201009]

(Received November 30, 2010; Accepted February 3, 2011; Published March 30, 2011)

Keywords: magnesium, hydrogen embrittlement, mechanical properties, fracture, Charpy impact test

\section{Introduction}

Magnesium alloys are promising light structural materials owning to their high specific strength and high specific stiffness. However, Mg alloys often exhibit low ductility and low fracture toughness at room temperature owning to few slip systems in the hexagonal close-packed structure. ${ }^{1)}$ One of the effective ways for improving the ductility and fracture toughness of $\mathrm{Mg}$ alloys is grain refinement ${ }^{2,3)}$ because it promotes the prismatic $\langle a\rangle$ slips, ${ }^{4)}$ and it facilitates the creation of a large plastic zone ahead of the fracture precrack. $^{5,6)}$ In addition, the control of texture ${ }^{7)}$ and the control of size and distribution of precipitates ${ }^{8)}$ are effective for the enhanced ductility and fracture toughness.

On the other hand, it is well known that the ductility and/ or fracture toughness can be significantly reduced by the presence of a small amount of hydrogen in many metals. ${ }^{9-11)}$ For example, even a very low hydrogen concentration of less than 1 mass ppm has a harmful effect on the ductility of Fe. ${ }^{12)}$ Watanabe et $a l .{ }^{13)}$ reported that the hydrogen concentration in a commercial pure $\mathrm{Mg}$ ingot is about 20 mass ppm at the atmospheric pressure and the room temperature. However, the solid solubility limit of hydrogen in $\mathrm{Mg}$ is only 0.08 mass ppm. ${ }^{14)}$ Thus, the commercial $\mathrm{Mg}$ ingots contain 250-fold excessive hydrogen, compared with the solid solubility limit.

Among the limited literatures, Chakrapani and Pugh ${ }^{15}$ ) reported the relation between hydrogen concentration and mechanical properties of $\mathrm{Mg}-\mathrm{Al}$ alloy, and revealed that hydrogen embrittlement is manifested by a deterioration of ductility in tensile tests, when the hydrogen concentration is set to be about 100 mass ppm. Noda et al. ${ }^{16)}$ investigated mechanical properties and microstructures of $\mathrm{Mg}-\mathrm{Al}$ alloy subjected to hydrogenation disproportion desorption recombination (HDDR) phenomena, and suggested that the HDDR phenomena is effective for an increase in surface strength due to grain refinement. At least to our knowledge, there has been no studies on the effects of hydrogen on the mechanical properties of $\mathrm{Mg}$, where hydrogen concentrations are the

*Corresponding author, E-mail: y-chino@aist.go.jp same as those of the commercially available $\mathrm{Mg}$ ingots (several tens mass ppm). $\mathrm{Mg}$ is known to be a typical hydrogen storing metal, and it can absorb a large amount of hydrogen up to 7.6 mass\% (66 at\%), as $\mathrm{MgH}_{2} .{ }^{17)}$ On the other hand, hydrogenation/dehydrogenation phenomena of $\mathrm{Mg}$ is very slow and occurs only at very high temperature, indicating that small amount of residual hydrogen in $\mathrm{Mg}$ may affect mechanical properties and fracture mechanism due to its strong hydrogen bonding strength. Thus, in the present study, tensile tests and Charpy impact tests are performed on pure cast $\mathrm{Mg}$ with hydrogen concentrations from 16 to 35 mass ppm.

\section{Experimental Procedure}

Using an induction furnace, as-received pure $\mathrm{Mg}$ ingots of mass $150 \mathrm{~g}$ were melted at $1013 \mathrm{~K}$ in a graphite mold in $\mathrm{Ar}$ atmosphere. To control the hydrogen concentration, degassing of the $\mathrm{Mg}$ melts was carried out in Ar atmosphere at a pressure of $450 \mathrm{~Pa}$ for 5 and $10 \mathrm{~min}$. Then, the melts were poured into rectangular steel molds with dimensions of $29 \times 49 \times 55 \mathrm{~mm}^{3}$. For reference, a pure $\mathrm{Mg}$ without degassing was also prepared.

The chemical compositions of the $\mathrm{Mg}$ without degassing and after degassing for $5 \mathrm{~min}$ are summarized in Table 1, where carbon was detected by the combustion method (LECO CS444), hydrogen was detected by the inert gas fusion method using thermal conductivity detector (LECO RH402), oxygen was detected by the inert gas fusion method using non-dispersive infrared detector (LECO TC600), nitrogen was detected by the inert gas fusion method using thermal conductivity detector (LECO TC600), and the other elements were detected by the inductively coupled plasmaatomic emission spectroscopy (Shimadzu ICPS-8100). The hydrogen concentration was 35 mass ppm for the $\mathrm{Mg}$ without degassing and 23 mass ppm for the $\mathrm{Mg}$ after degassing for 5 min, respectively, and there was a large difference only in hydrogen concentration, as shown in Table 1. For the $\mathrm{Mg}$ degassed for $10 \mathrm{~min}$, only the hydrogen concentration was measured, which was 16 mass ppm. Hereafter, the Mg specimens without degassing and those degassed for 5 and $10 \mathrm{~min}$ 
Table 1 Chemical compositions of the $\mathrm{Mg}$ without degassing and after degassing for $5 \mathrm{~min}$.

\begin{tabular}{|c|c|c|c|c|}
\hline & \multicolumn{2}{|c|}{ No degassing } & \multicolumn{2}{|c|}{ degassing for $5 \mathrm{~min}$} \\
\hline & $\begin{array}{c}\text { mass } \\
\text { fraction }\end{array}$ & $\begin{array}{l}\text { atomic } \\
\text { fraction }\end{array}$ & $\begin{array}{l}\text { mass } \\
\text { fraction }\end{array}$ & $\begin{array}{l}\text { atomic } \\
\text { fraction }\end{array}$ \\
\hline $\mathrm{H}$ & $35 \mathrm{ppm}$ & $850 \mathrm{ppm}$ & $23 \mathrm{ppm}$ & $560 \mathrm{ppm}$ \\
\hline $\mathrm{C}$ & $100 \mathrm{ppm}$ & $202 \mathrm{ppm}$ & $100 \mathrm{ppm}$ & $202 \mathrm{ppm}$ \\
\hline $\mathrm{N}$ & $21 \mathrm{ppm}$ & $36 \mathrm{ppm}$ & $25 \mathrm{ppm}$ & $43 \mathrm{ppm}$ \\
\hline $\mathrm{O}$ & $10 \mathrm{ppm}$ & $15 \mathrm{ppm}$ & $10 \mathrm{ppm}$ & $15 \mathrm{ppm}$ \\
\hline $\mathrm{Al}$ & $180 \mathrm{ppm}$ & $160 \mathrm{ppm}$ & $190 \mathrm{ppm}$ & $170 \mathrm{ppm}$ \\
\hline $\mathrm{Si}$ & $43 \mathrm{ppm}$ & $37 \mathrm{ppm}$ & $44 \mathrm{ppm}$ & $38 \mathrm{ppm}$ \\
\hline $\mathrm{Ca}$ & $3 \mathrm{ppm}$ & $2 \mathrm{ppm}$ & $1 \mathrm{ppm}$ & $1 \mathrm{ppm}$ \\
\hline Mn & $220 \mathrm{ppm}$ & $97 \mathrm{ppm}$ & $230 \mathrm{ppm}$ & $100 \mathrm{ppm}$ \\
\hline $\mathrm{Fe}$ & $25 \mathrm{ppm}$ & $10 \mathrm{ppm}$ & $23 \mathrm{ppm}$ & $10 \mathrm{ppm}$ \\
\hline $\mathrm{Ni}$ & $3 \mathrm{ppm}$ & $1 \mathrm{ppm}$ & $<1 \mathrm{ppm}$ & $<1 \mathrm{ppm}$ \\
\hline $\mathrm{Cu}$ & $29 \mathrm{ppm}$ & $11 \mathrm{ppm}$ & $26 \mathrm{ppm}$ & $10 \mathrm{ppm}$ \\
\hline $\mathrm{Zn}$ & $21 \mathrm{ppm}$ & $8 \mathrm{ppm}$ & $21 \mathrm{ppm}$ & $8 \mathrm{ppm}$ \\
\hline $\mathrm{Mg}$ & $\begin{array}{c}\text { Bal. } \\
(99.931 \%)\end{array}$ & $\begin{array}{c}\text { Bal. } \\
(99.8571 \%)\end{array}$ & $\begin{array}{c}\text { Bal. } \\
(99.9307 \%)\end{array}$ & $\begin{array}{c}\text { Bal. } \\
(99.8843 \%)\end{array}$ \\
\hline
\end{tabular}
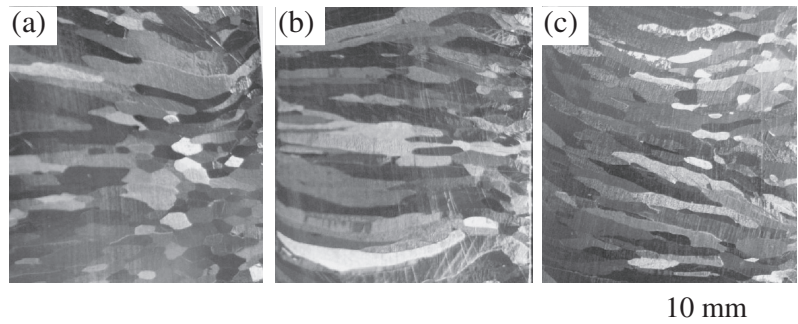

Fig. 1 Microstructures of pure Mg ingot: (a) $35 \mathrm{ppm}$ specimen, (b) $23 \mathrm{ppm}$ specimen and (c) $16 \mathrm{ppm}$ specimen, where the measured spot was indicated by broken line in Fig. 2

are referred to as the $35 \mathrm{ppm}$ specimen, the $23 \mathrm{ppm}$ specimen and the $16 \mathrm{ppm}$ specimen, respectively.

Figure 1 shows the optical micrographs of pure $\mathrm{Mg}$ ingots. The pure $\mathrm{Mg}$ ingots consisted of elongated grains, where the average grain size of short axis for the 16, 23 and $35 \mathrm{ppm}$ specimens was 632,503 and $674 \mu \mathrm{m}$, respectively; thus, there were minor differences in the grain size between the specimens. Hydrogen mapping in the $35 \mathrm{ppm}$ specimen was performed using a secondary ion mass spectrometry (SIMS) to detect hydrogen segregation sites.

Round bar specimens with $2.5 \mathrm{~mm}$ gage diameter and $10 \mathrm{~mm}$ gage length were machined for tensile tests. Tensile tests were carried out at room temperature with an initial strain rate of $1.7 \times 10^{-3} \mathrm{~s}^{-1}$. Also, the Charpy impact tests in the temperature range from 287 to $453 \mathrm{~K}$ were carried out with a Charpy impact machine (100J, Yonekura Seisakusho Co., Ltd.) using standard Charpy-V notch specimens $\left(10 \times 10 \times 55 \mathrm{~mm}^{3}\right)$. The ISO $148-1$ recommendations ${ }^{18)}$ were followed during the testing. Fracture surfaces obtained by the tensile tests and the Charpy impact tests were observed using an optical microscope and a scanning electron microscope, respectively. Figure 2 shows the sampling sites for round bar specimen and Charpy-V notch specimen. In the tensile tests, the tensile direction was set to perpendicular to

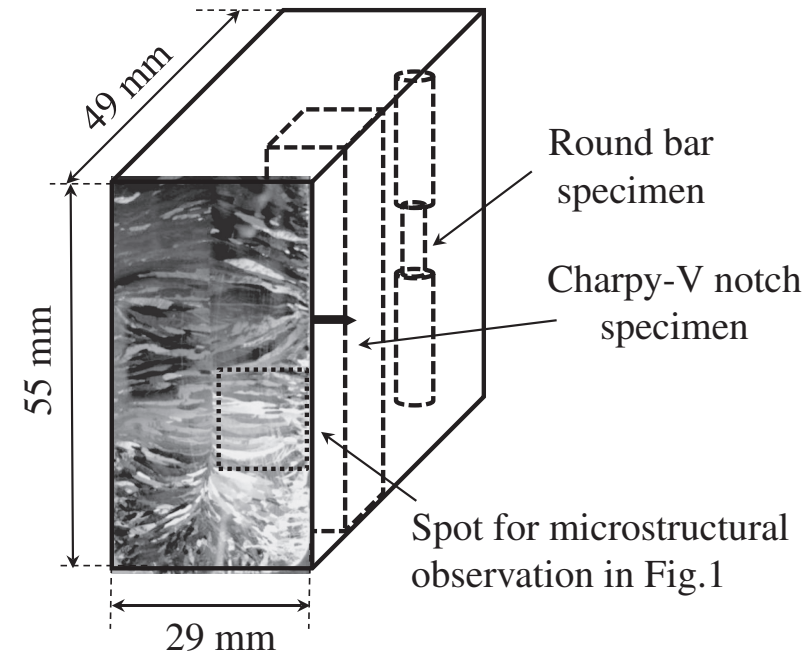

Fig. 2 Macrostructure of pure $\mathrm{Mg}$ ingot (23 ppm specimen) and the sampling sites for round bar specimen and Charpy-V notch specimen.

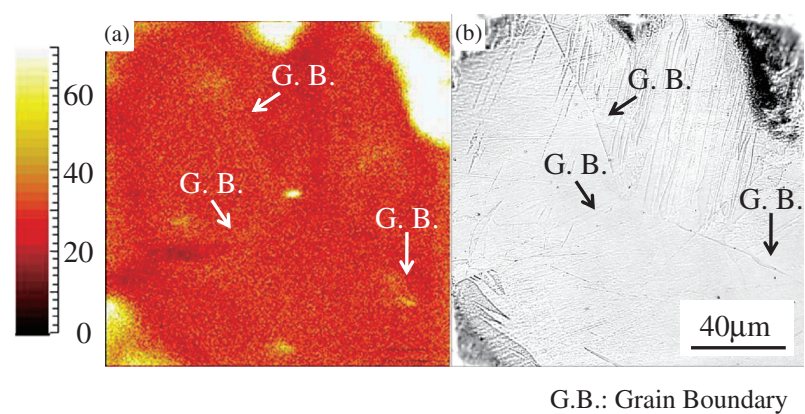

Fig. 3 Hydrogen mapping using SIMS and related optical micrograph for the 35 ppm specimen: (a) hydrogen mapping and (b) optical micrograph.

the long axis of elongated grains. In the Charpy impact tests, the direction of crack propagation was set to perpendicular to the long axis of elongated grains.

\section{Results and Discussion}

The hydrogen mapping obtained using the SIMS for the $35 \mathrm{ppm}$ specimen and the related optical micrograph are shown in Fig. 3, where the bright color means the higher intensity of hydrogen than the dark color, although the bright areas at the bottom left and at the top right are not the high intensity sites of hydrogen because of the pitted areas for pinpointing the location of observation. Hydrogen segregation was mainly observed at the triple junction of grain boundaries. Hydrogen segregation sites of the $35 \mathrm{ppm}$ specimen was almost the same as that of the $\mathrm{Mg}$-Al alloys with high hydrogen concentration, ${ }^{16,19)}$ where hydrogen segregation was observed at grain boundaries, in particular, at the triple junctions, ${ }^{19)}$ indicating that grain boundaries, in particular, triple junctions are the preferential segregation sites of hydrogen in pure $\mathrm{Mg}$.

The nominal stress-nominal strain curves obtained from tensile tests at room temperature for the 16 and $35 \mathrm{ppm}$ specimens are shown in Fig. 4. There were minor differences in the tensile properties of the specimens. Figure 5 exhibits the optical microstructures of the 16 and $35 \mathrm{ppm}$ specimens 


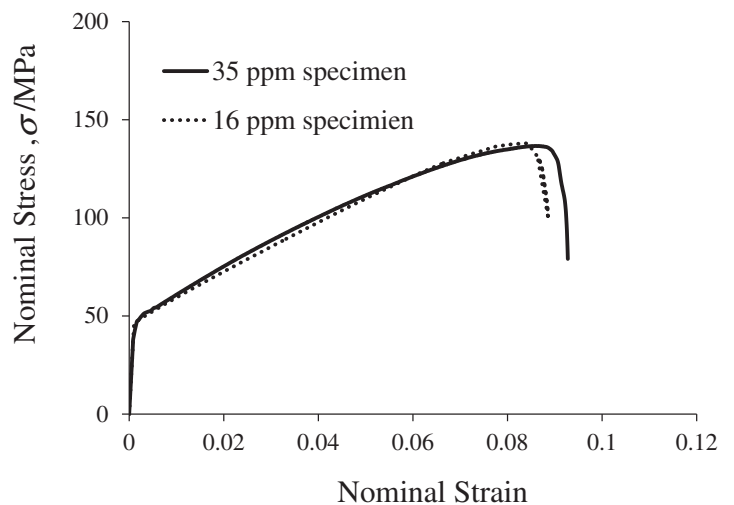

Fig. 4 Nominal stress-nominal strain curves obtained from tensile tests at room temperature for the 16 and $35 \mathrm{ppm}$ specimens.

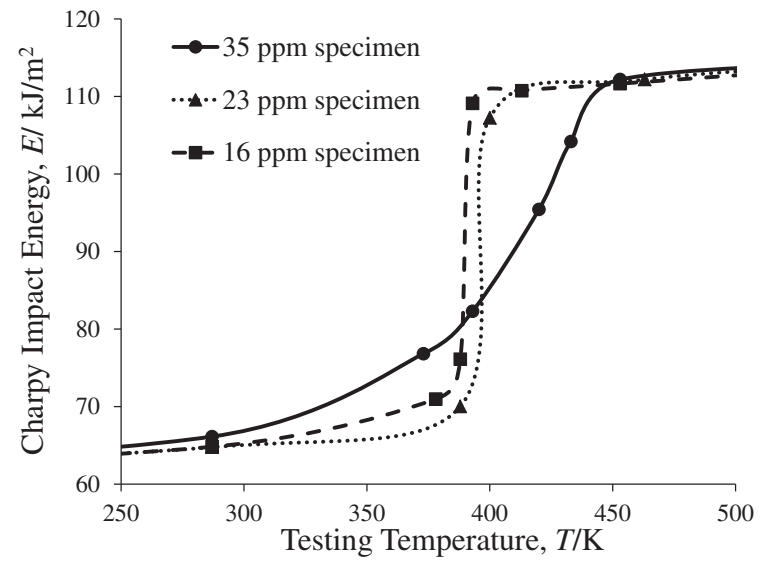

Fig. 6 The variation in Charpy impact energy as a function of temperature.
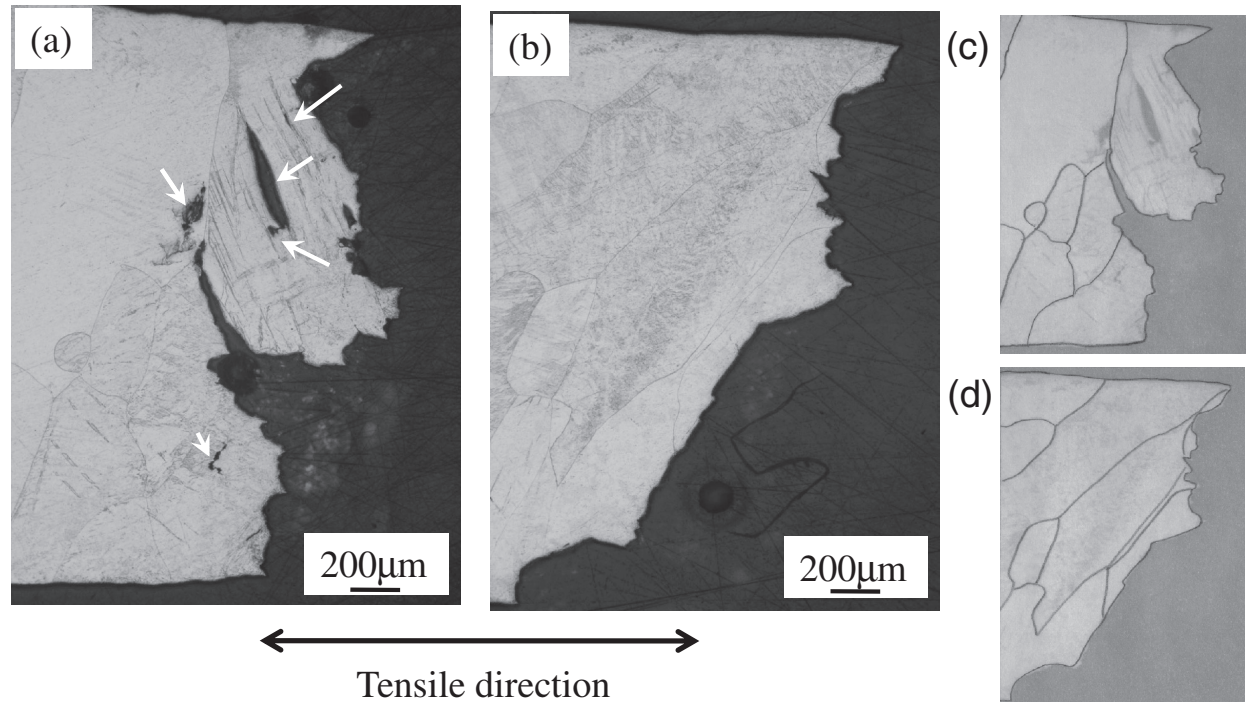

Fig. 5 Optical micrographs of the specimens deformed to failure in tensile tests: (a) 16 ppm specimen, (b) 35 ppm specimen, (c) 16 ppm specimen (contour of grain boundary is superimposed) and (d) $35 \mathrm{ppm}$ specimen (contour of grain boundary is superimposed), where the white arrow in Fig. 5(a) indicates the fracture site in grain.

deformed to failure in the tensile tests. It is observed that more transgranular cracks (indicated by the white arrows) occurred in the $16 \mathrm{ppm}$ specimen compared with the $35 \mathrm{ppm}$ specimen regardless of the same tensile properties. It is suggested that more cracks occurred at the grain boundaries in the $35 \mathrm{ppm}$ specimen compared with the $16 \mathrm{ppm}$ specimen, and hydrogen segregation at grain boundaries observed in the $35 \mathrm{ppm}$ specimen likely induced the intergranular cracking.

Figure 6 shows the temperature dependence of absorbed energy of pure $\mathrm{Mg}$ ingots by Charpy impact tests at various temperatures. As can be seen in Fig. 6, all the specimens exhibited a ductile-to-brittle transition. In the case of the 16 and $23 \mathrm{ppm}$ specimens, those absorbed energy quickly decreased from 110 to $70 \mathrm{~kJ} / \mathrm{m}^{2}$ at 380 and $390 \mathrm{~K}$, respectively. However, in the case of the $35 \mathrm{ppm}$ specimen, the sharp transition was not observed, and its absorbed energy gradually decreased from 450 to $400 \mathrm{~K}$. Obviously, the ductile-brittle transition temperature (DBTT) increased with increasing hydrogen concentrations, and the fracture mechanisms varied with hydrogen concentration. It is of interest to note that the DBTTs of Mg are higher than those for iron and steel, whose DBTTs are generally lower than $300 \mathrm{~K}^{20-22)}$ The high DBTT of Mg may be closely associated with an activity of non-basal slips, whose critical resolved shear stress (CRSS) significantly decreases with increasing temperature at around $423-523 \mathrm{~K}^{1 \text { ) }}$

Another interesting result is that both the $16 \mathrm{ppm}$ and 35 ppm specimens exhibited a large elongation of about $10 \%$, despite both the specimens had a much higher DBTTs compared with testing temperature of tensile tests. Ductility of $\mathrm{Mg}$ alloy at room temperature is known to be closely related to an activity of cross-slips, ${ }^{4)}$ which is thermally activated cross-slipping of screw dislocations from a basal plane to prismatic plane. Thus, it is suggested that the large strain rate dependence of cross-slip in $\mathrm{Mg}$ is probably ascribed to the differences in deformation characteristics between the tensile and impact tests.

The fracture surfaces of the $35 \mathrm{ppm}$ specimens after Charpy impact tests at 287 and $453 \mathrm{~K}$ are shown in Fig. 7. The fracture surface tested at above DBTT was completely ductile, and the entire surface consisted of dimples. However, the cleavage surface, which consisted of flat facets, was observed at below DBTT. Figure 8 shows the ductility fracture ratio for the specimens as a function of test 


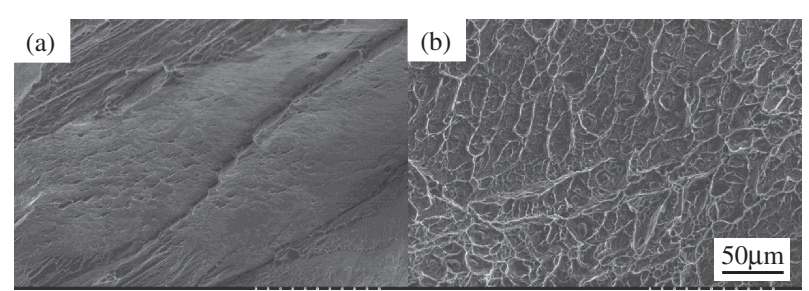

Fig. 7 Fracture surfaces of the $35 \mathrm{ppm}$ specimen after the Charpy impact tests: (a) $287 \mathrm{~K}$ and (b) $453 \mathrm{~K}$.

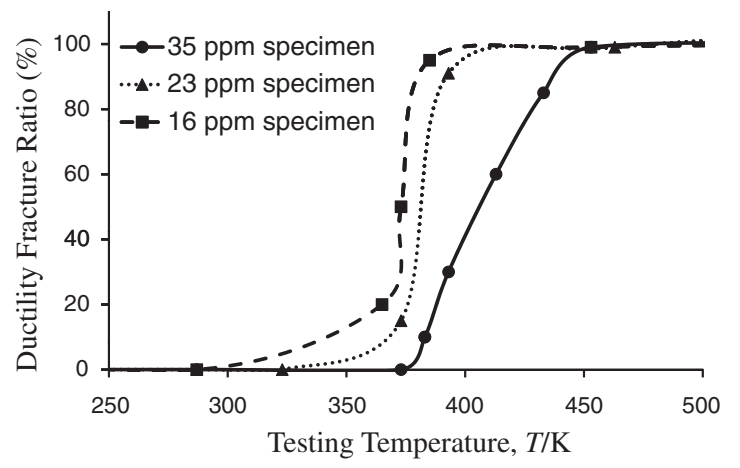

Fig. 8 The variation in ductility fracture ratio as a function of temperature, where the ductility fracture ratio is the ratio of the ductile fracture area to the total area.

temperature, where the ductility fracture ratio is defined by the ratio of the ductile fracture area to the total area. The trend of ductile fracture ratio was in good agreement with that of the Charpy impact energy, suggesting that in the DBTT regime, the overall fracture process was governed by cleavage mode of failure.

The experimental results obtained in this study demonstrated that the segregation of hydrogen at grain boundaries induces the intergranular fracture of $\mathrm{Mg}$, even when the hydrogen concentrations are several tens mass ppm. Kuramoto et al. ${ }^{19)}$ investigated hydrogen behavior during stress-corrosion cracking in an extruded AZ31 Mg alloy, whose grain size was several tens $\mu \mathrm{m}$, and proposed that pipe diffusion caused by an accumulation of dislocations related to plastic deformation may promote an acceleration of hydrogen movement toward crack tip, resulting in brittle stress-corrosion cracking. Direct comparison between the results by Kuramoto et al. ${ }^{19)}$ and our results may be difficult because of the large differences in grain size and hydrogen concentration. However, it is suggested that the hydrogen embrittlement observed in our results is also likely attributed to segregation of hydrogen at grain boundaries due to stress concentration related to tensile and impact deformations, since there is no qualitative difference in the transition of fracture mode with variation in hydrogen concentration between them.

Nevertheless, there are still some unclear points in order to clarify the hydrogen embrittlement mechanism of $\mathrm{Mg}$ with several tens mass ppm. Direct observation of hydrogen segregation sites near fracture surface by using hydrogen microprint technique ${ }^{19)}$ and/or tritium autoradiography ${ }^{23)}$ is still in progress. Further research is underway to understand the origin of hydrogen embrittlement in $\mathrm{Mg}$.

\section{Summary}

The effects of hydrogen on the tensile and fracture properties of magnesium have been investigated by performing the tensile tests and the Charpy impact tests on pure cast $\mathrm{Mg}$ with hydrogen concentrations of 16-35 mass ppm. Hydrogen mapping by secondary ion mass spectrometry revealed that the hydrogen was mainly segregated at triple junctions of grain boundaries. As shown by tensile tests at room temperature, although the tensile properties were hardly affected by the hydrogen concentration, crack formation at grain boundaries was observed to be induced by an increase in hydrogen concentration. The Charpy impact tests in the temperature range from 287 to $463 \mathrm{~K}$ showed that the DBT temperature increased with increasing hydrogen concentration, and that the temperature dependence of the Charpy impact energy was in good agreement with that of fractography. Thus, it is suggested that the segregation of hydrogen at grain boundaries likely enhanced the intergranular fracture of $\mathrm{Mg}$, even when the hydrogen concentration was several tens mass ppm.

\section{Acknowledgement}

This study was partially supported by JSPS Grant-in-Aid for Scientific Research (C) (KAKENHI, 22605007).

\section{REFERENCES}

1) H. Yoshinaga and R. Horiuchi: Trans. JIM 4 (1963) 1-8.

2) D. V. Wilson: J. Inst. Metals 98 (1970) 133-143.

3) K. Kubota, M. Mabuchi and K. Higashi: J. Mater. Sci. 34 (1999) 22552262.

4) J. Koike, T. Kobayashi, T. Mukai, H. Watanabe, M. Suzuki, K. Maruyama and K. Higashi: Acta Mater. 51 (2003) 2055-2065.

5) H. Somekawa and T. Mukai: Scr. Mater. 53 (2005) 1059-1064

6) H. Somekawa and T. Mukai: Scr. Mater. 54 (2006) 633-638.

7) H. Somekawa and T. Mukai: Scr. Mater. 53 (2005) 541-545.

8) H. Somekawa and T. Mukai: Mater. Trans. 47 (2006) 995-998

9) F. Garofalo, Y. T. Chou and V. Ambegaokar: Acta Metall. 8 (1960) 504-512.

10) G. M. Bond, I. M. Robertson and H. K. Birnbaum: Acta Metall. 36 (1982) 2193-2197.

11) G. Girardin and D. Delafosse: Scr. Mater. 51 (2004) 1177-1181.

12) K. Farrell and A. G. Quarrell: J. Iron Steel Inst. 202 (1964) 1002-1011.

13) T. Watanabe, Y. C. Huang and R. Komatsu: J. Jpn. Inst. Light Met. 26 (1976) 67-75.

14) T. Watanabe, Y. C. Huang and R. Komatsu: J. Jpn. Inst. Light Met. 26 (1976) 76-81.

15) D. G. Chakrapani and E. N. Pugh: Metall. Trans. A 7 (1976) 173178.

16) M. Noda, S. Ishida and K. Funami: J. Jpn. Inst. Light Met. 59 (2009) 13-18.

17) A. Zaluska, L. Zaluski and J. O. Ström-Olsen: J. Alloy. Compd. 288 (1999) 217-225.

18) ISO 148-1, Metallic materials-Charpy pendulum impact test-Part 1: Test method, 2009.

19) S. Kuramoto, I. Araki and M. Kanno: J. Jpn. Inst. Light Met. 51 (2001) 397-402.

20) E. Wakai, M. Sato, T. Sawai, K. Shiba and S. Jitsukawa: Mater. Trans. 45 (2004) 407-410.

21) J. Syarif, T. Tsuchiyama and S. Takai: ISIJ Int. 43 (2003) 1100-1104.

22) L. Schafer: J. Nucl. Mater. 283-287 (2000) 707-710.

23) H. Okada, G. Itoh and M. Kannno: Scr. Metall. Mater. 26 (1992) 69-74. 